\title{
Elaboração de pães com adição de farelo de soja
}

\author{
Manufactured breads with addition of soy bran
}

\author{
Eloísa Maria Morguete' \\ José Raniere Mazile Vidal Bezerra² \\ Katielle Rosalva Voncik Córdova ${ }^{3(*)}$ \\ Maurício Rigo ${ }^{4}$
}

Resumo

O objetivo desta pesquisa foi à elaboração de um produto de panificação diferenciado, com a adição de farelo de soja em sua formulação. Os pães foram elaborados com 5, 10 e 15\% de resíduo de soja em substituição à farinha de trigo. A formulação com $10 \%$ de farinha de soja foi preferida pelos provadores. Os pães elaborados com farelo de soja apresentaram teor de proteínas muito superior aos pães tradicionais, por volta de 10,6\%.

Palavras-chave: pão; farelo de soja; análise sensorial.

\section{Abstract}

The aim of this research was the making of bread added soy residues. Bread had been made with 5, 10 and $15 \%$ of soy residue in substitution to the wheat flour. Three formulations had presented good acceptance for the judges, being that with $10 \%$ of soy bran was preferred. The bread made with soy bran presented protein content higher than conventional bread, approximately $10.6 \%$.

Key words: bread; soy bran; sensory evaluation.

I Engenheira de Alimentos; Empresa Pietrobon, Unidade Industrial, Guarapuava, Paraná, Brasil; E-mail: eloisamorguete@yahoo.com.br

2 Dr.; Engenheiro de Alimentos; Professor do Departamento de Engenharia de Alimentos da Universidade Estadual do Centro-Oeste, UNICENTRO; Guarapuava, Paraná, Brasil; E-mail: raniere@unicentro.br

3 MSc.; Engenheira de Alimentos; Professora colaboradora do Departamento de Engenharia de Alimentos da Universidade Estadual do Centro-Oeste, UNICENTRO; Endereço: Rua Simeão Camargo Varela de Sá, 03, CEDETEG, CEP: 85040-080, Guarapuava, Paraná, Brasil; E-mail: kvcordova@hotmail.com (*) Autora para correspondência.

4 Dr.; Engenheiro de Alimentos; Professor do Departamento de Engenharia de Alimentos da Universidade Estadual do Centro-Oeste, UNICENTRO; Guarapuava, Paraná, Brasil; E-mail: mauriciorigo@yahoo.com.br

\begin{tabular}{llllll}
\hline Ambiência Guarapuava (PR) & v.7 n.3 & p.48I-488 Set./Dez. 20II & ISSN I808 - 025I
\end{tabular}




\section{Introdução}

O pão é um alimento que resulta do cozimento de uma massa feita com farinha de certos cereais, principalmente trigo, água e sal. Os diversos tipos de pães decorrem dos diferentes tipos de farinha e de levedura utilizadas, assim como da forma de cozimento. De acordo com Pizzinatto e Magno (1994), o pão já existia a 10.000 a.C., sendo formado pela mistura de farinha e água e cozido em pedras quentes. Como o pão não continha fermento para seu crescimento, este se apresentava de forma achatada, duro por fora e macio por dentro. Ao longo do tempo foram introduzidos a fermentação e o cozimento para melhoria dos produtos, uma vez que os consumidores estão cada vez mais exigentes. Assim, o pão é o produto obtido pela cocção, em condições tecnologicamente adequadas, de uma massa fermentada ou não, preparada com farinha de trigo e água, podendo ser elaborado com outras farinhas que contenham proteínas formadoras de glúten, além de outros ingredientes (MORETTO, 2002).

A soja é uma matéria-prima agrícola de grande interesse mundial graças à versatilidade de aplicação de seus produtos na alimentação humana e animal e ao seu valor econômico nos mercados nacional e internacional. O Brasil encontra-se entre os maiores produtores de soja do mundo, sendo o segundo maior produtor mundial depois dos Estados Unidos. (BORRMANN et al., 2009). De acordo com Bookwalter et al. (1975), a soja contém lisina em excesso e apresenta um balanceamento satisfatório de outros aminoácidos essenciais, exceto a metionina. A mistura de soja e trigo pode suplementar as proteínas, aumentando a sua eficiência protéica (PER) (SAMBUCETTI et al., 1976; GONZALEZ-AGRAMON e SERNA-SALDIVAR, 1988).

O farelo resultante da extração do óleo, pelo seu alto teor em proteína, é um importante ingrediente na elaboração de ração animal. Para o caso do consumo humano, o farelo de soja é moído e peneirado em peneira de 100 mesh, dando origem à farinha de soja desengordurada, sendo muito utilizado no enriquecimento protéico de pães, bolachas, tortas e outros tipos de alimentos de confeitaria, apresentando um teor de proteína ao redor de 47\% e baixas percentagens de gordura e fibras.

A adição apropriada de derivados de soja resulta em produtos alimentícios menos calóricos, com teor de lipídios reduzido e com elevado conteúdo de proteína, adequando-se desta forma às necessidades nutricionais de indivíduos adultos; com custo reduzido e preservação das características físicas e sensoriais do produto tradicional (DHINGRA, 2001; PIAZZON-GOMES, et al., 2010).

A indústria alimentícia busca o desenvolvimento de novos produtos cujas funções pretendam ir além do fornecimento de nutrientes básicos e da satisfação do paladar do consumidor (BEHRENS et al., 2001). Esses produtos são conhecidos como "alimentos funcionais" e têm como principal função à redução do risco de doenças crônico-degenerativas. Dentre os alimentos, cujas alegações de saúde têm sido amplamente divulgadas pela mídia nos últimos anos, destacam-se os produtos a base de soja. Hasler (1998) aponta que os produtos derivados de soja apresentam alto teor de proteínas de qualidade nutricional e que podem ser utilizada de forma preventiva e terapêutica no tratamento de doenças cardiovasculares, câncer, osteoporose e sintomas da menopausa. 
Nesse contexto, o objetivo deste trabalho foi elaborar pães com a adição de farelo de soja desengordurado, buscando apresentar ao mercado um produto diferenciado, agregando os benefícios que a soja pode trazer à saúde humana a um produto de boa aceitação.

\section{Material e métodos}

Obtenção da farinha de resíduo de soja

O farelo de resíduo de soja utilizado neste trabalho foi doado por uma indústria de beneficiamento de óleo de soja localizada na cidade de Maringá, PR. Na figura 1 é apresentado o processamento pelo qual o farelo de resíduo de soja passou na usina piloto do Departamento de Engenharia de Alimentos na Universidade Estadual do Centro-Oeste (UNICENTRO), para obtenção do farelo de soja desengordurado empregado nas formulações dos pães.

A secagem do farelo de resíduo de soja foi realizada em secador de bandejas a $60^{\circ} \mathrm{C}$ por 8 horas. Na figura 2 é apresentado o fluxograma de obtenção do farelo de soja desengordurado.

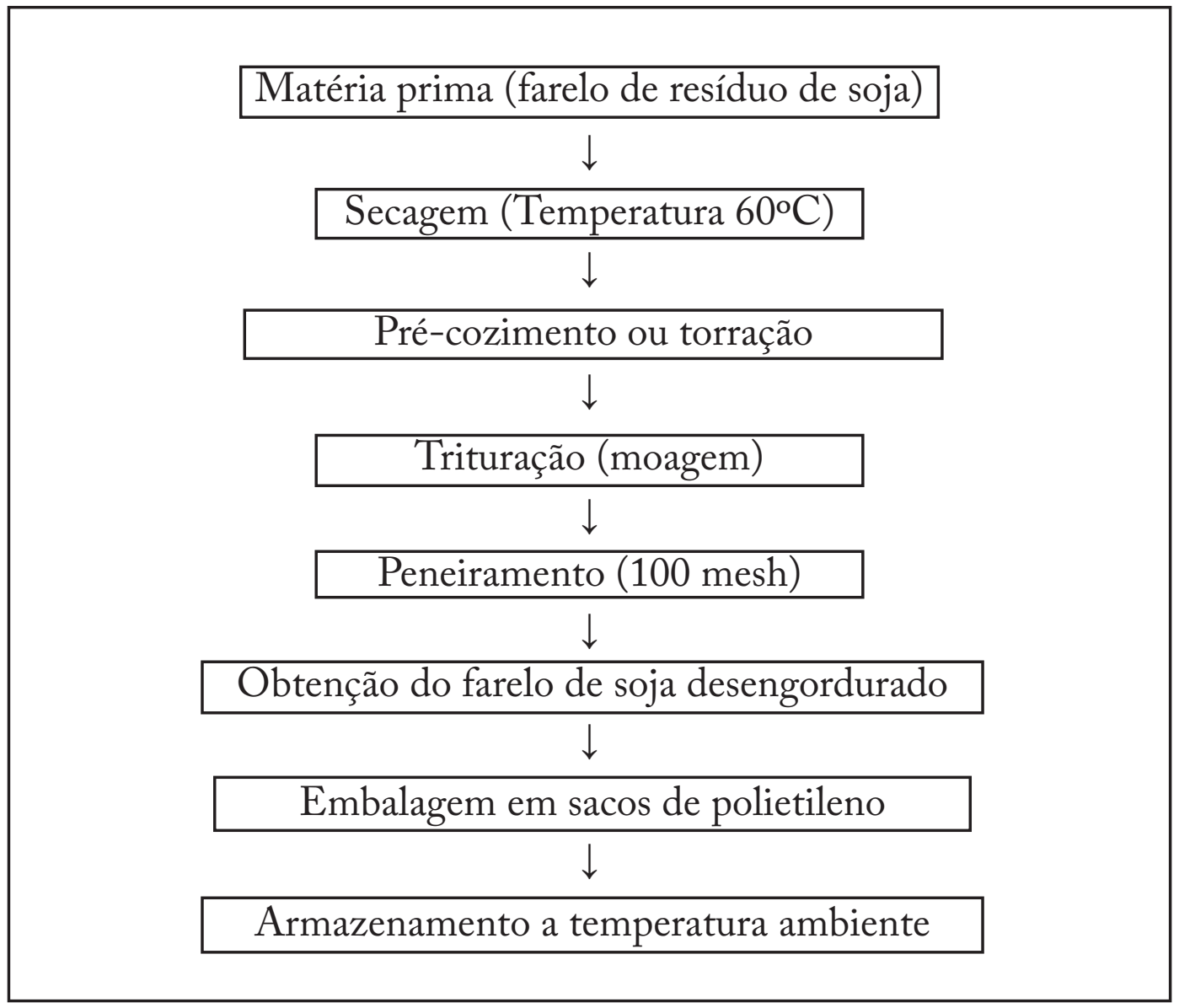

Figura I. Fluxograma de obtenção do farelo de soja desengordurado 


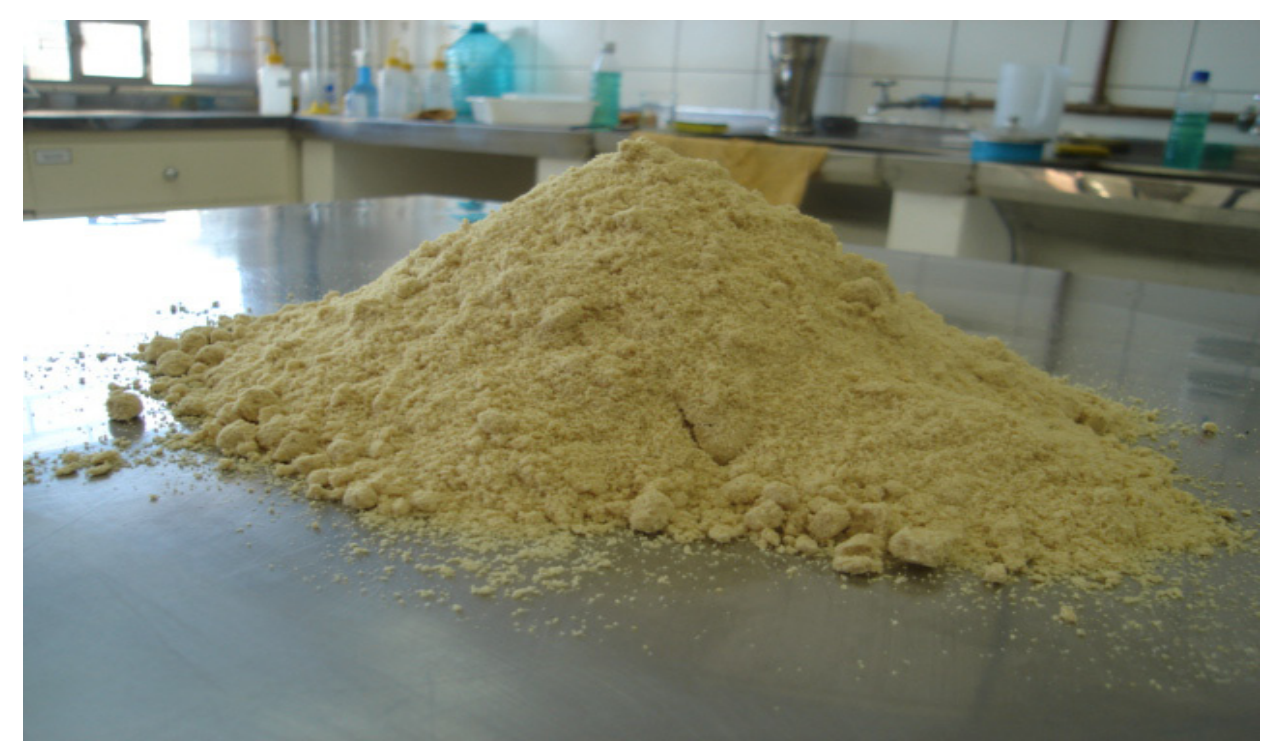

Figura 2. Farelo de soja desengordurado

\section{Obtenção dos pães com farelo de resíduo de soja}

Os pães com a adição de farelo de resíduo de soja foram elaborados na usina piloto de Panificação do Departamento de Engenharia de Alimentos na Universidade Estadual do Centro-Oeste, conforme figura 3. Na etapa de mistura foi adicionado o farelo de soja.

Os pães foram elaborados a partir de uma formulação básica e foram testadas três variações quanto ao teor de farelo de soja $(5 \%, 10 \%$ e $15 \%)$.

\section{Análises físicas e químicas}

Os teores de umidade, cinzas, proteínas, e lipídios do farelo de soja e do pão com 10\% de farelo foram determinados seguindo-se a metodologia do Instituto Adolfo Lutz
(2008). Os teores de fibras e carboidratos foram determinados pela metodologia oficial da Association of Official Analytical Chemists - AOAC (2000). As análises foram realizadas em triplicata.

\section{Análise Sensorial}

A aceitabilidade do produto foi avaliada através de uma escala hedônica de 9 pontos, ancorados nos extremos com 1 (desgostei extremamente) e 9 (gostei extremamente), por uma equipe de 50 julgadores não treinados, recrutados entre acadêmicos e funcionários da Universidade Estadual do Centro-Oeste. O painel sensorial foi conduzido no Laboratório de Análise Sensorial do Departamento de Engenharia de Alimentos, em cabines individuais com luz amarela. As amostras foram servidas em pratos brancos codificados com números de 3 dígitos aleatórios. Os resultados foram avaliados estaticamente pela Análise de 


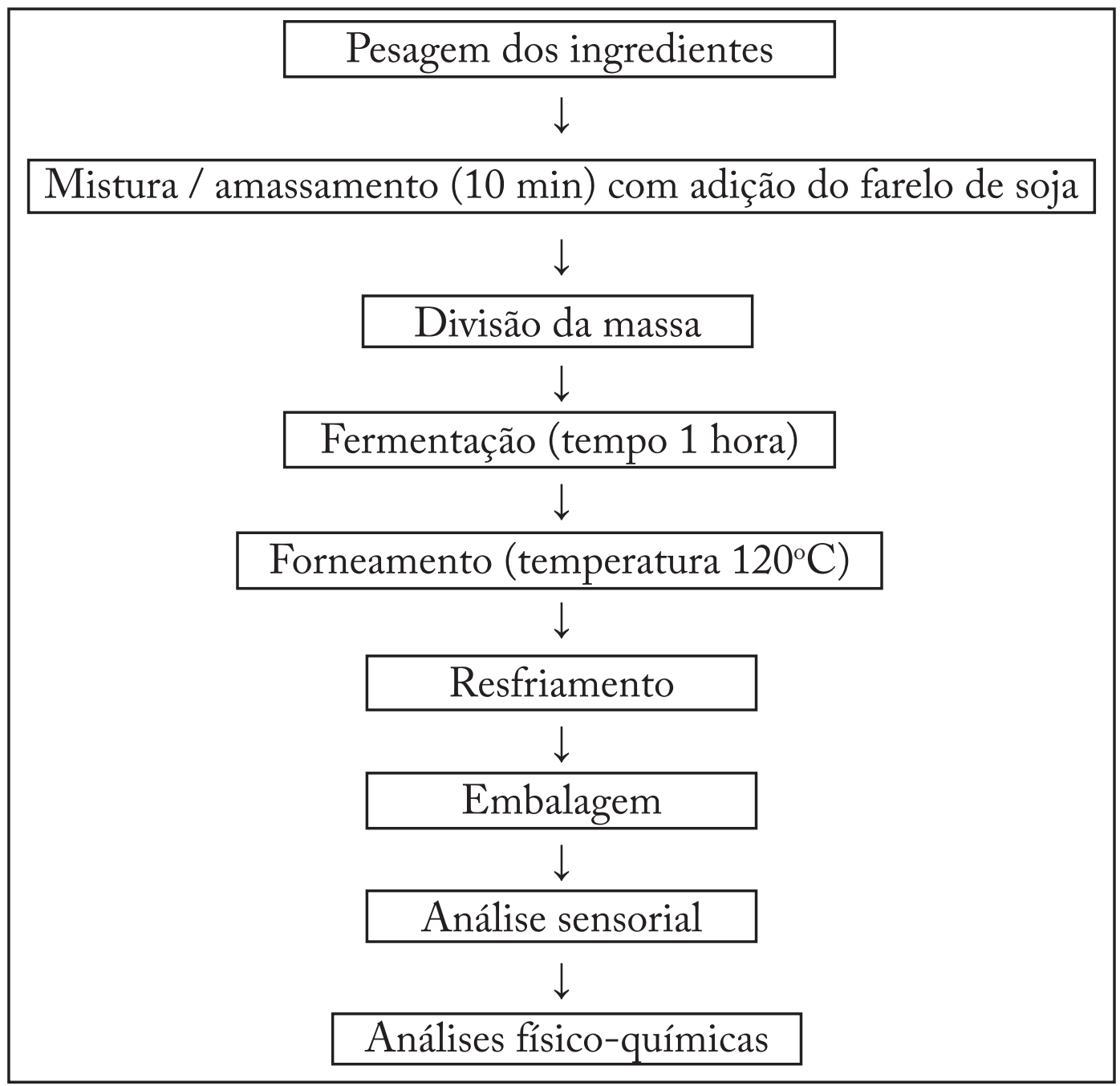

Figura 3. Fluxograma de obtenção do pão com farelo de soja desengordurado

Variância (ANOVA) e pelo Teste de Tukey ao nível de $5 \%$, de acordo com o proposto por Dutcosky (2009).

\section{Resultados e discussão}

A tabela 1 apresenta a composição centesimal do farelo de soja, destacando-se o alto teor de proteínas. Na figura 4 são apresentados os pães elaborados com adição de farelo de soja com $15 \%, 10 \%$ e $5 \%$, respectivamente. Não foi observada nenhuma diferença de coloração entre as crostas das amostras. Os pães apresentaram uma estrutura compacta não quebradiça, textura macia, alvéolos pequenos e miolo ligeiramente escuro.

Tabela I. Composição centesimal farelo de soja desengordurado

\begin{tabular}{cc}
\hline Composição & Média (\%) \\
\hline Umidade & $5,86 \pm 0,32$ \\
Cinzas & $5,60 \pm 0,25$ \\
Fibras & $8,57 \pm 0,15$ \\
Proteínas & $35,79 \pm 0,20$ \\
Lipídios & $12,83 \pm 0,20$ \\
Carboidratos & $31,35 \% \pm 0,17$ \\
\hline
\end{tabular}




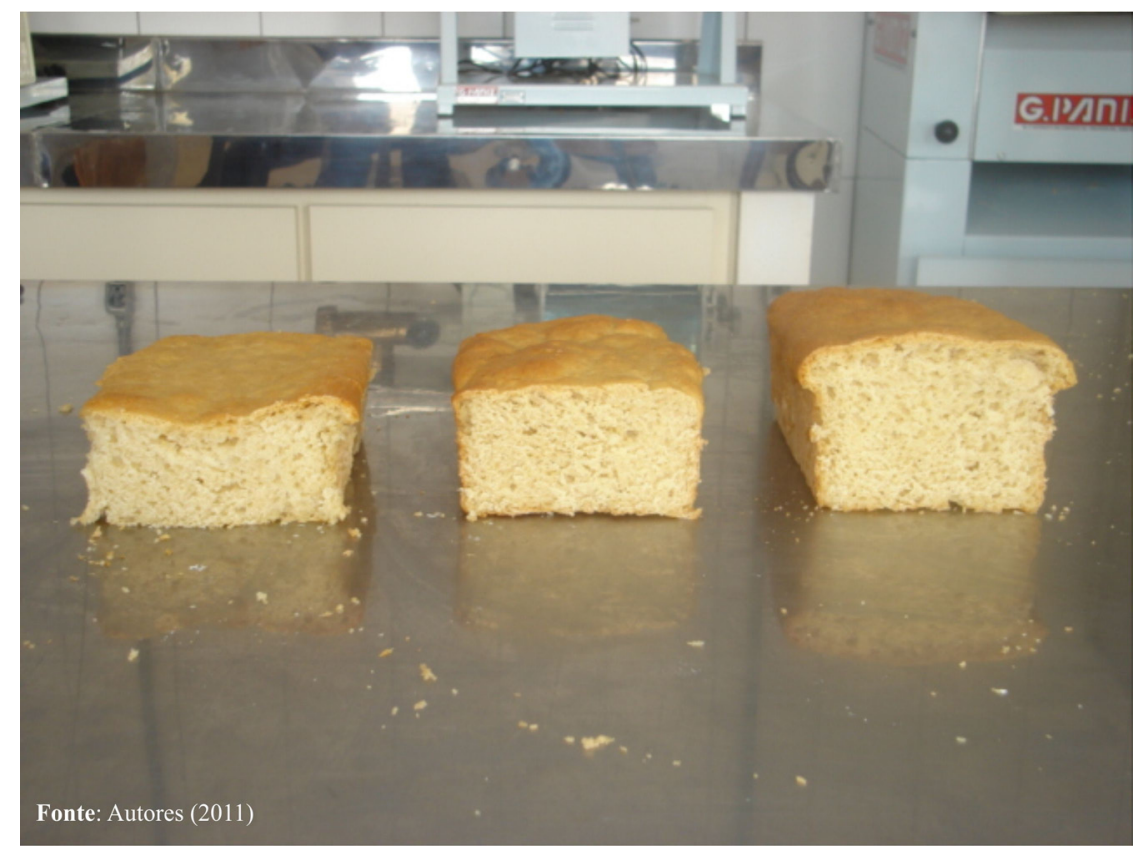

Figura 4. Pães com adição de $15 \%$, $10 \%$ e $5 \%$ de farelo de soja, respectivamente

$\mathrm{Na}$ tabela 2 são apresentadas as médias das notas atribuídas pelos provadores no teste de aceitabilidade dos pães com 5, 10 e 15\% de farinha de resíduo de soja.

Tabela 2. Notas atribuídas pelos provadores para os pães com adição de farinha de resíduo de soja

\begin{tabular}{cc}
\hline $\begin{array}{c}\text { Teor de farinha de } \\
\text { resíduo de soja }\end{array}$ & $\begin{array}{c}\text { Média das notas } \\
\text { atribuídas pelos } \\
\text { provadores* }^{*}\end{array}$ \\
\hline $5 \%$ & $5,80^{\mathrm{b}} \pm 1,53$ \\
$10 \%$ & $7,00^{\mathrm{a}} \pm 1,29$ \\
$15 \%$ & $5,76^{\mathrm{b}} \pm 1,30$ \\
\hline
\end{tabular}

Nota: * Letras iguais em uma mesma linha não diferem entre si estatisticamente $(p<0,05)$ - DMS (diferença mínima significativa) de 0,63

A partir dos dados verifica-se que não haver diferença significativa ao nível de 5\% entre as amostras adicionadas com 5\% e 15\% de farinha de resíduo de soja. No entanto, os pães com adição de $10 \%$ de farelo de soja diferiram-se dos demais ao nível de $5 \%$ de significância. Assim, a formulação com $10 \%$ de farelo de soja foi estatisticamente preferida pelos julgadores, sendo indicada para elaboração dos pães.

Bowles e Demiate (2006) elaboraram pães francês com okara de soja (subproduto do extrato aquoso - leite de soja) e obtiveram uma aceitação bastante próxima para os pães elaborados com 5\% e 10\% de okara, 8,0 e 7,8, respectivamente. Já para a amostra contendo $15 \%$ de okara, o valor da média alcançada foi de 6,6, demonstrando uma redução de sua aceitabilidade.

A tabela 3 apresenta a composição centesimal dos pães elaborados com $10 \%$ de farelo de soja desengordurado, comparado com pães brancos (isento de farelo de soja). De acordo com os resultados verifica-se um aumento do teor de proteínas em torno de $45 \%$ em média para a amostra, com ligeiras diferenças nos outros parâmetros. Isto garante o desenvolvimento de um 
Tabela 3. Características físicas e químicas do pão com e sem adição do farelo de soja desengordurado

\begin{tabular}{ccc}
\hline Parâmetros & $\begin{array}{c}\text { Média para pão sem adição de } \\
\text { farelo de soja desengordurado }- \\
\text { padrão (\%) }\end{array}$ & $\begin{array}{c}\text { Média para pão com adição de } \\
\text { farelo de soja desengordurado } \\
\text { (\%) }\end{array}$ \\
\hline Umidade & $36,1 \pm 0,23$ & $37,1 \pm 0,27$ \\
Cinzas & $1,0 \pm 0,17$ & $1,4 \pm 0,19$ \\
Fibras & $3,1 \pm 0,25$ & $3,9 \pm 0,32$ \\
Proteínas & $7,3 \pm 0,12$ & $10,6 \pm 0,14$ \\
Carboidratos & $39,5 \pm 0,24$ & $31,4 \pm 0,27$ \\
Lipídios & $13,1 \pm 0,18$ & $15,6 \pm 0,15$ \\
\hline
\end{tabular}

produto diferenciado, agregando qualidade nutricional ao produto final a partir de matérias-primas de baixo custo.

\section{Conclusão}

Dantas et al. (2009) elaboraram pães com $50 \%$ de okara de soja (subproduto do extrato aquoso - leite de soja) e obtiveram aproximadamente $25 \%$ de proteínas para suas formulações. Esse resultado mostra um teor elevado de proteínas, porém no quesito sensorial quanto maior a quantidade de okara utilizada menor é a aceitação dos produtos.

A elaboração de pães com farelo de soja desengordurado mostrou-se viável e as amostras apresentaram boa aceitabilidade. Os pães que tiveram formulações enriquecidas com $10 \%$ de farelo de soja desengordurado foram preferidos em análise sensorial e a caracterização deste produto apresentou índice elevado de proteínas em relação à formulação padrão.

\section{Referências}

ASSOCIATION OF OFFICIAL ANALYTICAL CHEMISTS - AOAC. Official methods of analysis of AOAC International, 17thed, v. 02, Gaithersburg, 2000.

BEHRENS, J. H.; ROIG, S. M.; DA SILVA, M. A. A. P. Aspectos de Funcionalidade, de Rotulagem e de Aceitação de Extrato Hidrossolúvel de Soja Fermentado e Culturas Lácteas Probióticas. Boletim da Sociedade Brasileira de Ciência e Tecnologia de Alimentos, Campinas, v. 34, n. 2, p. 99-106, 2001.

BOOKWALTER, G. N.; ANDERSON, R. A.; MUSTAKAS, G. C.; GRIFFIN JUNIOR, E. L. Fortification of dry soybean-based foods with DL-methionine. Journal of Food Science, Chicago, v.40, n.2, p.266-272, 1975.

BORRMAN, D.; JUNQUEIRA, R. M.; SINNECKER, P.; GOMES, M. S. O.; CASTRO, I.A.; MARQUES,U.M.L. Chemical and biochemical characterization of soybean produced under drought stress. Ciência e Tecnologia de Alimentos, Campinas, v.29, n.3, p. 676-681, jul./set. 2009.

BOWLES, S.; DEMIATE, I. M. Caracterização físico-química de okara e aplicação em pães do tipo francês. Ciência e Tecnologia de Alimentos, Campinas, v.26, n.3, p. 652-659, jul-set, 2006. 
DANTAS, M.I. S.; ANDRADE, G. F.; PIOVESAN, N.D.; MARTINO, H. S. D. Farinhas mistas de trigo e de soja agregam valor nutricional e sensorial em pães. Revista do Instituto Adolfo Lutz, São Paulo, v.68, n.2, p. 209-214, 2009.

DHINGRA, S.; JOOD, S. Organoleptic and nutritional evaluation of wheat breads supplemented with soybean and barley flour. Food Chemistry, v.77, n.4, p. 479-488, 2001.

DUTCOSKY, S. D. Análise Sensorial de Alimentos. 2. ed. Curitiba: Universitária Champagnat, 2009.239p.

GONZALEZ-AGRAMON, M.; SERNA-SALDIVAR, S. O. Effect of defatted soybean and soybean isolate fortification on the nutritional, physical, chemical and sensory properties of wheat flour tortillas. Journal of Food Science, v.53, p.793-797, 1988.

HASLER, C. M. Functional Foods: Their Role in Disease Prevention and Health Promotion. Food Technology, v.52, n.11, 1998.

INSTITUTO ADOLFO LUTZ (São Paulo). Normas analíticas do Instituto Adolfo Lutz: métodos físico-químicos para análise de alimentos. (Coord.) ZENEBON, O.; PASCUET, N. S.; TIGLEA, P. 4. ed., 1. ed. digital, São Paulo: Instituto Adolfo Lutz, 2008.

MORETTO, E. Introdução à Ciência de Alimentos. Florianópolis: Ed. UFSC, 2002.255p.

PIAZZON-GOMES, J.; PRUDÊNCIO, S.H.; SILVA, R. S. S. F. Queijo tipo minas frescal com derivados de soja: características físicas, químicas e sensoriais. Ciência e Tecnologia de Alimentos, Campinas, v.30, Supl.1, p. 77-85, maio 2010.

PIZZINATTO, A.; MAGNO, C.P. R. S. Curso Tecnologia de Processamento e Avaliação de Qualidade de Pão, Macarrão e Biscoito. Campinas: ITAL, 1994. 57 p.

SAMBUCETTI, M. E.; SCICLI, G. G.; SANAHUJA, J. C. Enriquecimiento de la harina de trigo con harinas de soya y girasol para la obtención de productos de panadería. Archivos Latinoamericanos de Nutrición, Caracas, v.26, n.3, p.353-364, 1976. 